\title{
Depression among Medical versus Non-Medical Students in Umm Al-Qura University, Makkah Al-Mukaramah, Saudi Arabia
}

\author{
Mohammad M. Alkot' ${ }^{1}$, Abdullah Y. Alnewirah ${ }^{2}$, Abdulaziz T. Bagasi ${ }^{2}$, Adel A. Alshehri \\ Naif A. Bawazeer ${ }^{3}$ \\ ${ }^{1}$ Department of Family Medicine, Menoufia University, Shebien Alkoum, Egypt \\ ${ }^{2}$ Internship, Umm Al-Qura University, Makkah Al-Mukaramah, Saudi Arabia \\ ${ }^{3}$ Department of Otolaryngology, Head \& Neck Surgery, Umm Al-Qura University, Makkah, Saudi Arabia \\ Email address: \\ Mohammed_elkott@yahoo.com (M. M. Alkot), Abdullah.Alnewirh@gmail.com (A. Y. Alnewirah), \\ Abdalaziz.Bagasi@gmail.com (A. T. Bagasi),Dr.life17@hotmail.com (A. A. Alshehri), Naaifbm@hotmail.com (N. A. Bawazeer)
}

\section{To cite this article:}

Mohammad M. Alkot, Abdullah Y. Alnewirah, Abdulaziz T. Bagasi, Adel A. Alshehri, Naif A. Bawazeer. Depression among Medical versus Non-Medical Students in Umm Al-Qura University, Makkah Al-Mukaramah, Saudi Arabia. American Journal of Psychiatry and Neuroscience. Vol. 5, No. 1, 2017, pp. 1-5. doi: 10.11648/j.ajpn.20170501.11

Received: March 10, 2016; Accepted: November 25, 2016; Published: January 5, 2017

\begin{abstract}
Background: Depression is a worldwide health problem affecting people who have a stressful life like medical students. Objectives: of the study is to estimate the depression rate and levels among medical versus non-medical students in Umm Al-Qura University, Makkah Al-Mukaramah, Saudi Arabia. Methods: A cross-sectional study based on Beck's Depression Inventory Questionnaire was conducted on a representative sample of medical and non-medical students of Umm Al-Qura University. The sample was randomly selected from both males and females of College of Medicine and two randomly selected non-medical colleges (College of Islamic Studies and College of Engineering \& Islamic Architecture). The male students were 103, 107 and 95 however the females students were 77 and 70 respectively. Results: The study illustrated a higher rate of depression among males than females (31.2\% versus $26.4 \%$ respectively). The levels of depression among males were near each other in the Colleges of Medicine and Engineering (36.9\% and 34.8\% respectively), while it was the lowest in College of Islamic Studies (22.7\%). On the other hand, the rate was 31.1\% and $21.1 \%$ among female students of College of Medicine and College of Islamic Studies respectively. So, both male and female medical students have the highest rate of depression. Conclusion: The biopsychosocial health of medical students is our concern. Thus, the study recommends improving the methods of teaching, creating a motivational learning environment and initiating stress management strategies to overcome the occurrence of depression.
\end{abstract}

Keywords: Depression, Stress, Biopsychosocial, Medical Education, Umm Al-Qura University

\section{Introduction}

Depression is a worldwide health problem affecting people at any age especially those who have a stressful life that in turn influence their social, economic, psychological, and mental health. Depression affects the brain causing changes in mood and response to things that the person is usually has a pleasure with. It may make the person irritable and induces the person to commit suicide. Since the medical education is one of the stressful fields around the world, we assume that there is a high prevalence rate of depression among medical students.

Few studies were done in some Saudi universities since 2007, these studies showed close results. A study done in AlQassim University in 2007 showed that the prevalence of depression among male medical students was $44 \%$ and $60 \%$, while among female students it was $66 \%$ and $89.7 \%$ in the first versus last year respectively [1]. These results were 
similar to those in other countries' universities. The authors considered changing in the way of learning and feeling of responsibility as the causes of increased rate of depression in the first year of college.

The prevalence of depression was different among King Saud University students, it was $48.2 \%$ divided into mild $(21 \%)$, moderate (17\%) and severe (11\%) [2]. Another study showed a positive correlation between depression and anxiety among 450 female medical students at King Abdulaziz University, depression percentage found to be $14.7 \%$ while anxiety was $34.9 \%$, considering the depression as the first predictor of morbid anxiety [3].

Studying stress and its effects on medical students at King Saud University, showed a positive correlation between progress in study years and stress rate [4].

The aim of this study is to estimate depression rate and levels among medicals versus non-medical colleges to reflect a clear image about this problem among Saudi medical versus non-medical students.

\section{Methodology}

A comparative cross-sectional study was conducted on a randomly selected sample of medical and non-medical students of Umm Al-Qura University, Makkah AlMukaramah, Saudi Arabia in 2015. The sample was randomly selected from male section of randomly selected three different colleges (College of Medicine, College of Islamic Studies and College of Engineering and Islamic Architecture) and from female section of Medical College and College of Islamic studies only because there is no College of Engineering and Islamic Architecture for females in Umm Al-Qura University.

The Arabic version of Beck's Depression Inventory Questionnaire was used to diagnose and estimate the levels of depression. The initial version was published in 1961 and reviewed twice in 1978 and 1996. It was formed from 21 questions that measure the levels of sadness, failure, disappointment, suicide thoughts, difficulty of sleep, losing weight and other factors.

Participant students were invited to fill the questionnaire in the middle of the second term of the academic year $2014 / 2015$ to avoid exams stress. Filling of the forms was voluntary and self-administered.

The level of depression of each student was estimated after summing the answers marks from 0 to 3 of all questions (No. $21)$, then they were categorized in the following categories: normal (1-10), mild mood disturbance (11-16), borderline clinical depression (17-20), moderate depression (21-30), severe depression (30-40) and over 40 indicate extreme depression.

Ethical approval was taken from the ethical committee of scientific research of college of medicine at Umm Al-Qura University. The aim of the study was clearly explained verbally with ensuring privacy to all study participants and it was written on the head of the questionnaire.

Data Management
Data will be fed into the computer using Statistical Package for Social Sciences (SPSS) software program V.20 to estimate the difference between some indicators. Data will be presented using descriptive statistics in the form of frequencies and percentages for qualitative variables. Variables will be compared using A Nova for three qualitative categorical groups and chi-square test for only two groups. Statistical significance will be set at p-value $<0.05$.

\section{Results}

Out of all participant students (No. 452 with age ranged from 18 - 25 years), $318(70.4 \%)$ were in normal and mild mood disturbance ranges while 134 students $(29.7 \%)$ were in borderline and different levels of depression according to Beck's Depression Inventory score.

The male students in the area of depression were 304 $(31.2 \%)$ divided by their levels as Borderline clinical depression, Moderate, Severe and Extreme depression $(11.8 \%, 13.2 \%, 4.9 \%$ and $1.3 \%$ respectively). That is higher than the percentage of depressed female students (No. 148 $26.4 \%$ ) who are divided by the same category into $11.5 \%$, $12.8,1.4 \%$ and $0.7 \%$ respectively.

A comparison between the three colleges including both male and female students, the level of depression was $34.8 \%$ in Engineering College, followed by $34.5 \%$ in the Medical College and finally $22 \%$ in Islamic Studies College. Also, by comparing male sections of colleges, there was no significant difference in levels of depression between Medical and Engineering Colleges, (36.9\% and $34.8 \%$ respectively). Whereas, it was the lowest in Islamic Studies College $(22.7 \%)$. On the other hand regarding the female sections of Medical and Islamic Studies colleges, the percentages of students who were in the area of depression are $31.1 \%$ of Medical students and $21.1 \%$ of Islamic Studies students. Islamic Studies students get the highest percentage of normal and mild mood disturbance scores $(77.3 \%)$ comparing to Medical and Engineering students $(63.1 \%$ and $65.2 \%$ respectively). Nearly the same results were found in female section $(78.9 \%$ and $68.9 \%$ respectively)

\section{Discussion}

It is well noted that medical students often suffer from many difficulties in medical school. If these problems are not solved, they are likely to produce further stresses [7]. The high prevalence of depression among students, in general, is necessary to be diagnosed and managed. But, we concentrate on medical students particularly because this will affect their learning, patient care and ultimately will reflect on the whole community health. The choice of using Beck's Depression Inventory Questionnaire for screening was because the initial version was published in 1961 and reviewed twice in 1978 and 1996, this may give better accuracy.

Out of all studied students (No.452), 318 (70.4\%) were in normal and mild mood disturbance ranges, while 134 
students $(29.7 \%)$ were in borderline and different levels of depression. The present study illustrated the presence of high prevalence rate of depression among male students of all three different colleges in comparison to female ones. The rate of depression among male students was $31.2 \%$ in all three colleges, while it was $26.4 \%$ among female students in two colleges only which are College of Medicine and College of Islamic Studies (because there is no College of Engineering and Islamic Architecture for females in Umm Al-Qura University). This result disagrees with the result of a survey in a private university that found a non-significant gender-based difference in the level of anxiety and depression [8]. While higher levels of stress among females were also reported in the western literature $[9,10]$. The high prevalence rate of depression among male students in the current study may be attributed to their marriage during their university studies that may add more stress on the males, also, using different questionnaires may affect the result.

The present study illustrated a high prevalence rate of depression among students of the College of Medicine $(34.5 \%)$ in comparison to the college of Islamic studies (22\%) and College of Engineering and Islamic Architecture (34.8\%). However, this difference was not statistically significant. The study results agree with results of a comparison study in Saudi Arabia among females in College of Medicine and College of Applied Studies and Community Services (CASCS) at Dammam University. It showed that, more medical students $(48.6 \%)$ reported being frequently stressed due to their studies more than CASCS students $(38.7 \%, P<0.01)$, and medical students were at greater risk of physical and mental health problems than non-medical ones because of exposure to academic stress (5). While another comparison study at McGill University in medical, law and graduate students showed a little or no evidence of stress among medical students versus non-medical ones [11]. This is the first study in Saudi Arabia that compare depression between medical versus non-medical university students including both genders although they have separate campuses following the Islamic rules. In the current study, depression rates among male students in the College of Medicine and College of Engineering were near to each other (36.9\% and $34.8 \%$ respectively), while it was the lowest in Islamic Studies College $(22.7 \%)$. On the other hand, in the female section of Medical and Islamic Studies Colleges, the percentages of depressed students were $31.1 \%$ versus $21.1 \%$ (P- 0.619). So, male and female medical students had the highest level of depression and Islamic Studies Colleges had the lowest one. This result may be attributed to some factors that affect medical more than non-medical students like inappropriate teaching methods, poor learning environment and worry about failure which were commonly mentioned by medical more than non-medical students [5]. The stressors identified in one study were congested classrooms, troubles with teachers and fear of future [6]. Also, condensed academic courses, nationality (being non-Saudi) or having an emotional failure, all these make students more prone to anxiety and depression [3].

The higher prevalence of depression among male than female students is not corresponding to the results of many studies. In a research done at King Saud University, Riyadh, Saudi Arabia the prevalence of depression was higher among female medical students compared to males [4]. In a study at King Faisal University, Saudi Arabia showed that major depression and anxiety were significantly higher among females [12]. There is also another study done in Umm AlQura University showed that the prevalence of depressive symptoms was higher among female medical students than males $(34.2 \%$ versus $27 \%)$ [13].

Some studies showed suicidal ideation among medical students and young physicians. A nationwide prospective study reported that $14 \%$ had suicidal thoughts, $8 \%$ had planned suicide and $1.4 \%$ attempted suicide [14]. However, in the present study none of the participants found to have suicidal thoughts or ideation. This result may be explained by that, Quran or Islamic cultural values did not allow Muslims to commit suicide and who does it will be punished by God in the life after death. Also, some Turkish and Indian studies reported substance abuse and alcoholism among medical students and junior physicians under stress $[15,16]$. The present study did not explore substance abuse that cannot be ruled out without scientific research data.

Limitations of this study were; it is specific to one university only and not generalized to other institutions in the country, so it may not be representative of all students in Saudi Arabia. The results of female students were in the College of Medical and Islamic Studies only because there is no College of Engineering and Islamic Architecture for females at Umm Al-Qura University.

\section{Conclusion}

In conclusion, male and female students in the College of Medicine revealed the highest level of depression, however, only male students had a higher prevalence rate of depression in all three different colleges compared to females. The study pays more attention to improve the curriculum and methods of teaching, and to create a motivational learning environment. The study encourages who are responsible for medical education to initiate stress management strategies for better learning situation and subsequently better medical care.

\section{Acknowledgements}

The authors would like to thank Abdulaziz Alhaifi, Saeed Balubaid, Naif Alhowaiti and Bushra Alshehri for their facilitation in data collection. 


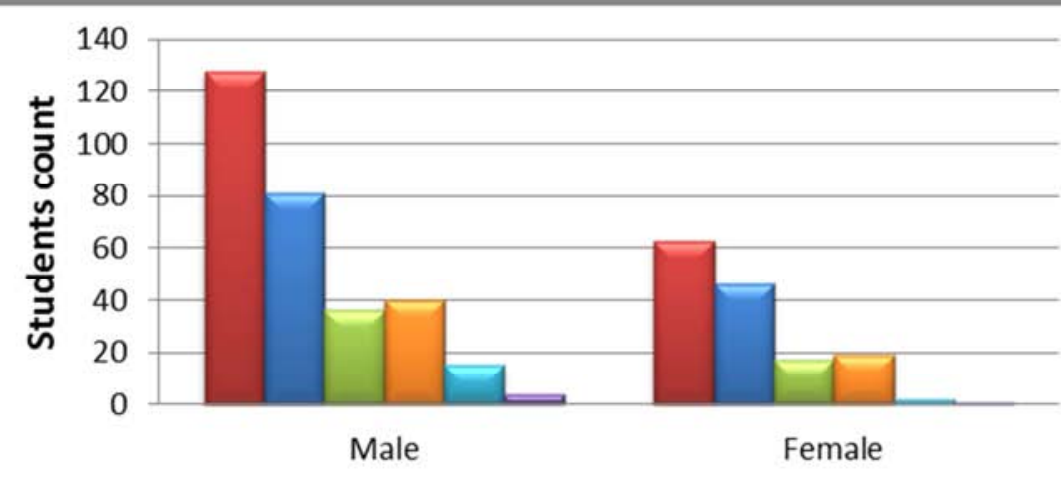

Students gender a Normal

Mild mood disturbance

$\square$ Borderline clinical depression

Moderate depression

$\square$ Sever depression

Extreme depression

$\mathrm{P}<0.05$

Figure 1. Levels of depression between male and female students.

Table 1. Levels of Depression between regarding the genders of students.

\begin{tabular}{|c|c|c|c|c|c|c|}
\hline & \multicolumn{2}{|c|}{$\begin{array}{l}\text { Medicine and } \\
\text { Surgery }\end{array}$} & \multicolumn{2}{|c|}{$\begin{array}{l}\text { Engineering and } \\
\text { Islamic } \\
\text { Architecture }\end{array}$} & \multicolumn{2}{|c|}{$\begin{array}{l}\text { Islamic } \\
\text { Studies }\end{array}$} \\
\hline & No & $\%$ & No & $\%$ & No & $\%$ \\
\hline Normal & 74 & $41.1 \%$ & 31 & $32.6 \%$ & 86 & $48.6 \%$ \\
\hline $\begin{array}{l}\text { Mild mood } \\
\text { disturbance }\end{array}$ & 44 & $24.4 \%$ & 31 & $32.6 \%$ & 52 & $29.4 \%$ \\
\hline $\begin{array}{l}\text { Borderline } \\
\text { clinical } \\
\text { depression }\end{array}$ & 23 & $12.8 \%$ & 12 & $12.6 \%$ & 18 & $10.2 \%$ \\
\hline $\begin{array}{l}\text { Moderate } \\
\text { depression }\end{array}$ & 28 & $15.6 \%$ & 14 & $14.7 \%$ & 17 & $9.6 \%$ \\
\hline $\begin{array}{l}\text { Severe } \\
\text { depression }\end{array}$ & 8 & $4.4 \%$ & 6 & $6.3 \%$ & 3 & $1.7 \%$ \\
\hline $\begin{array}{l}\text { Extreme } \\
\text { depression }\end{array}$ & 3 & $1.7 \%$ & 1 & $1.1 \%$ & 1 & $0.6 \%$ \\
\hline
\end{tabular}

$\mathrm{P}<0.05$

Table 2. Levels of Depression among Male students.

\begin{tabular}{lllllll}
\hline & \multicolumn{2}{l}{$\begin{array}{l}\text { Medicine and } \\
\text { Surgery }\end{array}$} & \multicolumn{2}{l}{$\begin{array}{l}\text { Engineering and } \\
\text { Islamic } \\
\text { Architecture }\end{array}$} & \multicolumn{2}{c}{$\begin{array}{l}\text { Islamic } \\
\text { Studies }\end{array}$} \\
\hline & No & $\%$ & No & $\%$ & No & $\%$ \\
\hline $\begin{array}{l}\text { Normal } \\
\begin{array}{l}\text { Mild mood } \\
\text { disturbance }\end{array}\end{array}$ & 22 & $21.4 \%$ & 31 & $32.6 \%$ & 28 & $26.4 \%$ \\
$\begin{array}{l}\text { Borderline } \\
\text { clinical } \\
\text { depression }\end{array}$ & 15 & $14.6 \%$ & 12 & $12.6 \%$ & 9 & $8.5 \%$ \\
$\begin{array}{l}\text { Moderate } \\
\text { depression }\end{array}$ & 15 & $14.6 \%$ & 14 & $14.7 \%$ & 11 & $10.4 \%$ \\
$\begin{array}{l}\text { Severe } \\
\text { depression }\end{array}$ & 6 & $5.8 \%$ & 6 & $6.3 \%$ & 3 & $2.8 \%$ \\
$\begin{array}{l}\text { Extreme } \\
\text { depression }\end{array}$ & 2 & $1.9 \%$ & 1 & $1.1 \%$ & 1 & $0.9 \%$ \\
\hline
\end{tabular}

$\mathrm{P}<0.05$
Table 3. Levels of Depression among Female students.

\begin{tabular}{lllll}
\hline & \multicolumn{2}{l}{$\begin{array}{l}\text { Medicine and } \\
\text { Surgery }\end{array}$} & \multicolumn{2}{l}{ Islamic Studies } \\
\hline & No & \% & No & \% \\
\hline Normal & 31 & $40.3 \%$ & 32 & $45.1 \%$ \\
Mild mood disturbance & 22 & $28.6 \%$ & 24 & $33.8 \%$ \\
Borderline clinical & 8 & $10.4 \%$ & 9 & $12.7 \%$ \\
depression & 13 & $16.9 \%$ & 6 & $8.5 \%$ \\
Moderate depression & 2 & $2.6 \%$ & 0 & $0.0 \%$ \\
Severe depression & 1 & $1.3 \%$ & 0 & $0.0 \%$ \\
Extreme depression & & & & \\
\hline
\end{tabular}

$\mathrm{P}<0.05$

\section{References}

[1] Inam SB. Anxiety and Depression among Students of a Medical College in Saudi Arabia. International journal of health sciences. 2007; 1(2): 295-300.

[2] Al-Faris EA, Irfan F, Van der Vleuten CP, Naeem N, Alsalem A, Alamiri $\mathrm{N}$, et al. The prevalence and correlates of depressive symptoms from an Arabian setting: a wake-up call. Medical teacher. 2012; 34Suppl 1: S32-6.

[3] Ibrahim N, Al-Kharboush D, El-Khatib L, Al-Habib A, Asali D. Prevalence and Predictors of Anxiety and Depression among Female Medical Students in King Abdulaziz University, Jeddah, Saudi Arabia. Iranian journal of public health. 2013; 42(7): 726-36.

[4] Abdulghani HM, AlKanhal AA, Mahmoud ES, Ponnamperuma GG, Alfaris EA. Stress and its effects on medical students: a cross-sectional study at a college of medicine in Saudi Arabia. Journal of health, population, and nutrition. 2011; 29(5): 516-22.

[5] Al-Dabal BK, Koura MR, Rasheed P, Al-Sowielem L, Makki SM. A Comparative Study of Perceived Stress among Female Medical and Non-Medical University Students in Dammam, Saudi Arabia. Sultan Qaboos University medical journal. 2010; 10(2): 231-40. 
[6] El-Gilany AH, Mar M, Hammad S. Perceived stress among male medical students in Egypt and Saudi Arabia: effect of sociodemographic factors. Ann Saudi Med 2008; 28(6): 442448 .

[7] Baldassin S, Silva N, de Toledo Ferraz Alves TC, CastaldelliMaia JM, Bhugra D, Nogueira-Martins MC, de Andrade AG, Nogueira-Martins LA. Depression in medical students: Cluster symptoms and management. J Affect Disord 2012.

[8] Inam S, Saquib A, Alam E. Prevalence of anxiety and depression among medical students of a private university. $\mathrm{J}$ Pak Med Assoc. 2003 Feb; 53(2): 44-7.

[9] John A, Towes MD, Jocelyn M, et al. "Analysis of stress levels among medical students residents and graduate students at four Canadian schools of medicine" Acad Med. 1997; 72: 997-1002.

[10] Rosal MC, Ockene IS, Ockene JK, Barrett SV, Ma Y, Hebert JR. "A longitudinal study of students' depression at one medical school” Acad Med. 1997 Jun; 72(6): 542-6.

[11] Helmers KF. Stress and depressed mood in medical students, law students and graduate students at Mc Gill University. Acad Med. 1997; 72: 708-14.
[12] Mostafa Amr, Tarek Tawfik Amin, SahooSaddichha,Sami Al Malki, Mohammed Al Samail, Nasser Al Qahtani, AbdulhadiAlAbdulHadi, Abdullah Al Shoaibi. Depression and anxiety among Saudi University students: prevalence and correlates. The Arab Journal of Psychiatry (2013) Vol. 24 No. 1 Page (1-7).

[13] Bander Khalid Jarwan Depression among medical students of Faculty of Medicine, Umm Al-Qura University in Makkah, Saudi Arabia. Int J Med Sci Public Health. 2015; 4(2): 184191.

[14] Tyssen R, Vaglum P, Gronvold NT, Ekeberg O. Suicidal ideation among medical students and young physicians: a nationwide and prospective study of prevalence and predictors. J Affective Disord. 2001 Apr; 64(1): 69-79.

[15] Akvardar Y, Demiral, Ergor G, Bilici M, Akil Ozer O. Substance abuse in a sample of Turkish medical students. Drug Alcohol Depend. 2003 Nov 24; 72(2): 117-21.

[16] Kumar P, Basu D. Substance abuse by medical students and doctors. J Indian Med Assoc.2000 Aug; 98(8): 447-52. 